\title{
Correspondence
}

Psychological Medicine, 48 (2018). doi:10.1017/S003329171700191X

First published online 17 July 2017

\section{Letter to the Editor \\ Exposure to nitrous oxide and intrusive memory formation in psychological trauma}

Das et al. (2016) conducted a study to assess the effect of nitrous oxide $\left(\mathrm{N}_{2} \mathrm{O}\right)$ on intrusions following a traumatic event. The researchers invited 50 adult participants to watch two graphic movie scenes, followed by a 30-min exposure of either $50 \%$ gas mixture of $\mathrm{N}_{2} \mathrm{O}$ in oxygen or medical air. Participants kept a daily record of intrusive memories for a week following the traumatic exposure. The authors noted that the incidence of intrusions decreased by as much as $50 \%$ the day after viewing in the $\mathrm{N}_{2} \mathrm{O}$ group. However, in participants experiencing dissociation following the traumatic event, $\mathrm{N}_{2} \mathrm{O}$ exposure produced an increased intrusion frequency. These results led the authors to conclude that $\mathrm{N}_{2} \mathrm{O}$ may speed the decline in intrusive memory frequency following a traumatic event, presumably through its inhibitory action on central glutamatergic signaling. Though, the reverse may be true in dissociated individuals, and this finding was underemphasized by the authors, as indicated by the study's title, and the subsequent media reports commenting on the study. This concern is underscored by previous paradoxical findings on the link between subanalgesic $\mathrm{N}_{2} \mathrm{O}$ exposure and human memory.

Ramsay et al. (1992) reported that subjects breathing $\mathrm{N}_{2} \mathrm{O}$ required a greater number of acquisition trials to reach a learning criterion (i.e., number-noun pairs). Though $\mathrm{N}_{2} \mathrm{O}$ exposure during acquisition of material decreased accessibility of the information, the ability to recall the material 2 weeks later improved compared with placebo. Importantly, correlational analyses suggested that this enhanced $\mathrm{N}_{2} \mathrm{O}$-mediated delayed recall did not appear to be dependent on the increased number of trials during acquisition in the $\mathrm{N}_{2} \mathrm{O}$-exposed group. Taken together, these findings suggest that $\mathrm{N}_{2} \mathrm{O}$ exposure during acquisition or in already dissociated individuals may affect enhanced delayed recall.

In addition to the links between $\mathrm{N}_{2} \mathrm{O}$ exposure and memory, we have proposed through repeated epidemiological investigations and review that exposure to trace levels of environmental emissions of $\mathrm{N}_{2} \mathrm{O}$, which, in addition to its clinical usefulness, also acts as a pervasive agricultural and combustion air pollutant, may precipitate neurodevelopmental impairment in vulnerable populations. Our epidemiological investigations to date have associated the use of nitrogen fertilizers in agriculture - as the most concentrated source of environmental $\mathrm{N}_{2} \mathrm{O}$ emissions - with hospitalization for attention-deficit hyperactivity disorder (ADHD), representing a severely impaired phenotype (Fluegge, 2016a; Fluegge \& Fluegge, 2017). Our review of this novel hypothesis discussed the known physiological mechanisms of low-dose $\mathrm{N}_{2} \mathrm{O}$ exposure from both in vitro and in vivo models, including disruption of the cholinergic system (Suzuki et al. 2003), endogenous release of dynorphin, and activation of the kappa opioid receptor (KOR) (Branda et al. 2000) as well as activation, at subanalgesic levels, of the corticotropinreleasing factor and brainstem noradrenergic nuclei (Zhang et al. 1999; Sawamura et al. 2003). Moreover, we cited preclinical animal studies and clinical evidence in human subjects demonstrating significant cognitive impairment and alterations in neurotransmission from trace levels of exposure to $\mathrm{N}_{2} \mathrm{O}$ (Fluegge, 2016a). Additionally, chronic recreational $\mathrm{N}_{2} \mathrm{O}$ may lead to psychiatric symptoms, including dissociation (van Amsterdam et al. 2015). These specific physiological targets may directly affect attentionrelated neural networking as well as neural correlates of trauma-related psychopathology (Fluegge, 2016b).

Pietrzak et al. (2014) conducted a novel brain-imaging study wherein they have linked the brain KOR to a constellation of symptoms among trauma victims. The authors administered a radioactive tracer to the KOR to all participants and compared the PET brain scans of healthy volunteers $v$. those clinically diagnosed with severe trauma-related psychopathology, including PTSD. Results indicated a negative correlation between KOR availability in the amygdala-anterior cingulate cortex-ventral striatal neural circuit and symptoms of loss (i. e., dysphoria), indicating that dynorphinergic excess may desensitize brain KOR, contributing to more intense dysphoric symptoms among prior trauma victims. Animal studies show that pharmacological KOR blockade administered before extinction sessions - and not before or after the conditioning - did not led to a decrease in freezing behavior in extinction sessions (Bilkei-Gorzo et al. 2012), confirming that excess dynorphinergic-mediated KOR desensitization or blockade may contribute to trauma-related psychopathology.

Chronic, intermittent exposure (i.e., $6 \mathrm{~h} /$ day, 5 days a week for 2 weeks) to trace levels of $\mathrm{N}_{2} \mathrm{O}$ pollution 
(i.e., as low as $50 \mathrm{ppm}, 0.005 \%$ ) decreased dopamine levels in the corpus striatum of CD-1 mice $(p<0.05)$ (Abdul-Kareem et al. 1991). The depression in dopamine levels may be associated with compensatory increases in striatal dynorphinergic activity (Steiner \& Gerfen, 1998), given the role that dynorphin opioid peptides play in $\mathrm{N}_{2} \mathrm{O}$-mediated antinociception especially at low doses before higher order anesthetic mechanisms are induced (Branda et al. 2000). Collectively, these studies support the hypothesis that exposure to $\mathrm{N}_{2} \mathrm{O}$ may affect memory formation in a time and exposure-dependent manner. Importantly, though, the extent of direct modulation of opioidergic signaling (i.e., KOR desensitization) after the traumatic event due to trace environmental $\mathrm{N}_{2} \mathrm{O}$-mediated dynorphinergic reactivity may not only enhance delayed recall among prior trauma victims, but also facilitate co-morbid psychiatric conditions, like ADHD (Spencer et al. 2016; Fluegge, 2016b), as our prior epidemiological investigations have discussed.

\section{Acknowledgements}

The author has indicated no financial relationships relevant to this article to disclose.

\section{Declaration of Interest}

The author reports no conflict of interest relevant to this article to disclose.

\section{Ethical Approval}

This paper does not contain any studies with human participants or animals performed by the author.

\section{References}

Abdul-Kareem HS, Sharma RP, Drown DB (1991). Effects of repeated intermittent exposures to nitrous oxide on central neurotransmitters and hepatic methionine synthetase activity in CD-1 mice. Toxicology and Industrial Health 7, 97-108.

Bilkei-Gorzo A, Erk S, Schürmann B, Mauer D, Michel K, Boecker H, Scheef L, Walter H, Zimmer A (2012). Dynorphins regulate fear memory: from mice to men. Journal of Neuroscience 32, 9335-9343. doi: 10.1523/ JNEUROSCI.1034-12.2012.

Branda EM, Ramza JT, Cahill FJ, Tseng LF, Quock RM (2000). Role of brain dynorphin in nitrous oxide antinociception in mice. Pharmacology, Biochemistry, and Behavior 65, 217-221.

Das RK, Tamman A, Nikolova V, Freeman TP, Bisby JA, Lazzarino AI, Kamboj SK (2016). Nitrous oxide speeds the reduction of distressing intrusive memories in an experimental model of psychological trauma. Psychological Medicine 46, 1749-1759. doi: 10.1017/S003329171600026X.

Fluegge K (2016a). Does environmental exposure to the greenhouse gas, $\mathrm{N}_{2} \mathrm{O}$, contribute to etiological factors in neurodevelopmental disorders? A mini-review of the evidence. Environmental Toxicology and Pharmacology 47, 6-18. doi: 10.1016/j.etap.2016.08.013.

Fluegge K (2016b). The association between PTSD and ADHD: does the association reveal a PTSD-somatoform subtype? A reply to Spencer et al. (2015). Journal of Clinical Psychiatry 77, e1149. doi: 10.4088/JCP.16lr10630.

Fluegge K, Fluegge K (2017). Exposure to ambient PM10 and nitrogen dioxide and ADHD risk: a reply to $\operatorname{Min} \& \operatorname{Min}(2017)$. Environment International 103, 109-110. doi: 10.1016/j. envint.2017.02.012.

Pietrzak RH, Naganawa M, Huang Y, Corsi-Travali S, Zheng MQ, Stein MB, Henry S, Lim K, Ropchan J, Lin SF, Carson RE, Neumeister A (2014). Association of in vivo $\kappa$-opioid receptor availability and the transdiagnostic dimensional expression of trauma-related psychopathology. JAMA Psychiatry 71, 1262-1270. doi: 10.1001/jamapsychiatry.2014.1221.

Ramsay DS, Leonesio RJ, Whitney CW, Jones BC, Samson HH, Weinstein P (1992). Paradoxical effects of nitrous oxide on human memory. Psychopharmacology (Berl) 106, 370-374.

Sawamura S, Obara M, Takeda K, Maze M, Hanaoka K (2003). Corticotropin-releasing factor mediates the antinociceptive action of nitrous oxide in rats. Anesthesiology 99, 708-715.

Spencer AE, Faraone SV, Bogucki OE, Pope AL, Uchida M, Milad MR, Spencer TJ, Woodworth KY, Biederman J (2016). Examining the association between posttraumatic stress disorder and attention-deficit/hyperactivity disorder: a systematic review and meta-analysis. Journal of Clinical Psychiatry 77, 72-83. doi: 10.4088/JCP.14r09479.

Steiner H, Gerfen CR (1998). Role of dynorphin and enkephalin in the regulation of striatal output pathways and behavior. Experimental Brain Research 123, 60-76.

Suzuki T, Ueta K, Sugimoto M, Uchida I, Mashimo T (2003). Nitrous oxide and xenon inhibit the human (alpha 7)5 nicotinic acetylcholine receptor expressed in Xenopus oocyte. Anesthesia and Analgesia 96, 443-448.

van Amsterdam J, Nabben T, van den Brink W (2015). Recreational nitrous oxide use: prevalence and risks. Regulatory Toxicology and Pharmacology 73, 790-796. doi: 10.1016/j.yrtph.2015.10.017.

Zhang C, Davies MF, Guo TZ, Maze M (1999). The analgesic action of nitrous oxide is dependent on the release of norepinephrine in the dorsal horn of the spinal cord. Anesthesiology 91, 1401-1407.

K. FLUEGGE*

Institute of Health and Environmental Research, Cleveland, $\mathrm{OH}$, USA

* Address for correspondence: K. Fluegge, Institute of Health and Environmental Research, Cleveland, Ohio 44118, USA. (Email: keithfluegge@gmail.com) 